\title{
Topografia dos órgãos abdominais em Didelphis albiventris
}

\section{Topography of abdominal organs in Didelphis albiventris}

\author{
Heloísa Pozzan Dal Moro, ${ }^{* *}$ Ana Paula de Souza Lima, ${ }^{* *}$ Juliano César Majolo, ${ }^{* *}$ Flávia Regina Tramontina, ${ }^{* *}$ Milena Rosa, ${ }^{* *}$ \\ Isadora Morais Massa, ${ }^{* *}$ Mirelly Medeiros Coelho**
}

\begin{abstract}
Resumo
O conhecimento da localização dos órgãos nas diferentes regiões do corpo do animal é essencial para a prática clínica, cirúrgica e para o diagnóstico por imagem. O objetivo do estudo foi descrever a anatomia topográfica abdominal do Didelphis albiventris. Foram utilizados quatro cadáveres (animais jovens), dois destes destinados para o estudo macroscópico em peças a fresco e os outros fixados em solução aquosa de formaldeído a 10\%. Os cadáveres foram dissecados e as estruturas anatômicas identificadas, analisadas e fotografadas. A maioria dos órgãos localizados na região abdominal dos cadáveres da espécie $D$. albiventris apresentou posição similar aos dos caninos, porém, alguns órgãos e a localização de determinadas estruturas apresentaram particularidades importantes, como a presença dos ossos epipúbicos, a ausência do lobo hepático quadrado, a presença de um ceco desenvolvido e o cólon dividido em três segmentos.
\end{abstract}

Palavras-chave: Didelphidae, gambá, regiões abdominais.

\begin{abstract}
The knowledge about localization of organs in different regions of the animal's body is essential for clinical, surgical and diagnostic imaging practice. The purpose of this study was to describe the abdominal topographic anatomy of Didelphis albiventris. Was used four dead bodys (young animals), two of these was intended for the macroscopic study of fresh pieces and the others fixed in $10 \%$ aqueous formaldehyde solution. The corpses was dissected and the anatomic structures was identified, analyzed and photographed. Most of the organs located in the abdominal region of cadavers from species D. albiventris presented structure and position similar to canines, however some of these organs and localization of structures presented important particularities, like the presence of epipubic bones, absence of square hepatic lobe, presence of an developed cecum and colon divided into three segments.
\end{abstract}

Keywords: Didelphidae, skunk, abdominal regions.

\section{Introdução}

Membros da família Didelphidea, comumente chamados gambás, apresentam-se amplamente distribuídos, com espécies que habitam o sul do Canadá, Estados Unidos, México, América Central e quase toda América do Sul. Do ponto de vista da anatomia do Didelphis albiventris, ainda existem inúmeros aspectos que merecem estudos mais aprofundados (Lindemann 2002). Em um levantamento realizado por Preuss (2015), o D. albiventris foi a espécie mais frequentemente encontrada em um trecho de rodovia no oeste de Santa Catarina após atropelamento.

Devido ao grande número de mamíferos atropelados na região, muitas vezes há a necessidade da realização de atendimentos clínicos e cirúrgicos, além de exames complementares como radiografia e ultrassonografia, que são modalidades de imagens que fazem parte da rotina clínica (Bortolini et al. 2013). Assim, torna-se essencial conhecer a topografia dos órgãos abdominais das espécies silvestres. Porém, a descrição da anatomia topográfica abdominal ainda é limitada, para a maioria das espécies de animais silvestres, inclusive para o $D$. albiventris.

O objetivo do estudo foi descrever a anatomia topográfica abdominal em $D$. albiventris para embasar procedimentos veterinários nesta espécie.

\section{Material e Métodos}

Foram utilizados quatro cadáveres (três machos e uma fêmea) da espécie $D$. albiventris, filhotes, coletados na rodovia da BR-282, no município de Chapecó-SC (autorização SISBIO 75346-1) e levados ao Laboratório de Anatomia da Universidade Comunitária da Região de Chapecó - Unochapecó.

Dos quatro cadáveres, um macho e uma fêmea foram destinados para os estudos macroscópicos em peças a fresco e os outros dois machos após a retirada da pele foram fixados em solução aquosa de formaldeído a $10 \%$, por aproximadamente sete

\footnotetext{
*Recebido em 19 de janeiro de 2021 e aceito em 4 de julho de 2021.

**Universidade Comunitária da Região de Chapecó, Unochapecó, Departamento de Anatomia Animal; Chapecó; Santa Catarina; Brasil. Autor para correspondência: myrellymvet@hotmail.com
} 
dias. Durante a dissecação os cadáveres foram posicionados em decúbito dorsal, posteriormente, foi realizada uma incisão ventral mediana desde a região xifoidea até a região púbica. Em seguida, foram rebatidas as paredes abdominais laterais e expostos os órgãos abdominais. Em sequência os órgãos e estruturas localizados na região abdominal cranial (subdividida em região hipocondríaca direita, esquerda e xifoidea), região abdominal média (subdividida em região abdominal lateral direita, esquerda e umbilical) e região abdominal caudal (subdividida em região inguinal direta e esquerda e púbica) foram fotografados, identificados e descritos topograficamente. A nomenclatura utilizada seguiu a descrição da Nomina Anatômica Veterinária (2017).

\section{Resultados}

Na região abdominal cranial observou-se o fígado, a vesícula biliar, o estômago, parte cranial do duodeno, parte do jejuno, o pâncreas, os rins, as glândulas adrenais e o baço. Precisamente na região hipocondríaca direita (Figuras 1 e 6), identificou-se parte do fígado, localizado entre o diafragma e a $13^{a}$ costela (o processo caudado do lobo caudado, o lobo hepático direito lateral e parte do lobo hepático direito medial na sequência dorsoventral). O lobo hepático direito medial era o maior. No teto da cavidade abdominal foi observado o rim direito, em três cadáveres a esqueletopia foi entre a $11^{a}$ e a $13^{a}$ costelas e em um animal entre a $12^{\mathrm{a}}$ costela e as duas primeiras vértebras lombares. Craniomedialmente ao rim direito observou-se a glândula adrenal direita, ambos se relacionavam ventralmente com o duodeno (partes cranial e descendente) e o pâncreas (lobo pancreático direito).

Dorsalmente na região hipocondríaca esquerda (Figuras 2 e 6), identificou-se o rim esquerdo, em nível sutilmente mais caudal que o rim direito; craniomedialmente a este órgão, identificouse a glândula adrenal esquerda. Na maioria dos cadáveres o baço localizou-se na altura entre a $8^{a}$ e a $12^{a}$ costela, porém em um cadáver encontrou-se entre a $11^{a}$ e a $13^{a}$ costela. O lobo hepático esquerdo lateral e parte do lobo hepático esquerdo medial encontraram-se dispostos desde o diafragma até ao nível da $10^{a}$ costela. $O$ estômago como um todo em três cadáveres apresentou-se localizado ao nível da $9^{\mathrm{a}}$ até a $12^{\mathrm{a}}$ costela e em um animal da $8^{\mathrm{a}}$ à $13^{\mathrm{a}}$ costela, devido a capacidade de expansão pela ingestão de alimento.

$\mathrm{Na}$ região xifoidea foram identificados parte do lobo hepático esquerdo medial, parte do lobo hepático direito medial e interposto entre eles a vesícula biliar (Figuras 3 e 6). Ainda, nessa região observou-se o jejuno.

Na região abdominal média encontraram-se partes do intestino delgado e do intestino grosso (Figura 6). Especificamente, na região abdominal lateral direita (Figura 1) identificou-se o duodeno descendente, ventralmente a este encontrou-se o ceco e o jejuno; também foi observada a presença das pregas ileocecal e cecocólica. O cólon descendente e o jejuno encontraram-se na região abdominal lateral esquerda (Figuras 2 e 4). Especificamente na região umbilical as alças jejunais encontraram-se em contato com o assoalho da cavidade abdominal.

$\mathrm{Na}$ região abdominal caudal, encontrou-se a vesícula urinária, dois prolongamentos ósseos (ossos epipúbicos), parte do cólon descendente e do reto (Figuras 5 e 6). A vesícula urinária ocupou todas as suas subdivisões (região inguinal direita, esquerda e região púbica), na região inguinal esquerda observou-se a parte final do cólon descendente e a porção inicial do reto. Os ossos epipúbicos percorreram a região púbica e suas porções craniais alcançaram as regiões inguinais direita e esquerda.



Figura 1: Fotomacrografia da cavidade abdominal de espécime jovem, macho, de $D$. albiventris, revelando região hipocondríaca direita (RHD) com o lobo hepático direito medial (FDM), lobo hepático direito lateral (FDL), processo caudado do lobo caudado $(F C)$, duodeno $(\mathrm{D})$ e rim direito $(\mathrm{RD})$. Região abdominal lateral direita (RALD) contendo o duodeno (D), ceco (C) e jejuno (J).

*As linhas tracejadas de cor branca delimitam aproximadamente a localização de regiões abdominais. 




Figura 2: Fotomacrografia da cavidade abdominal de espécime jovem, macho, de $D$. albiventris revelando a região hipocondríaca esquerda (RHE) com o lobo hepático esquerdo lateral (FEL), lobo hepático esquerdo medial (FEM), estômago (E), rim esquerdo (RE) e baço (B); Região abdominal lateral esquerda (RALE) contendo o cólon descendente (CD) e o jejuno (J).

*As linhas tracejadas de cor branca delimitam aproximadamente a localização de regiões abdominais.

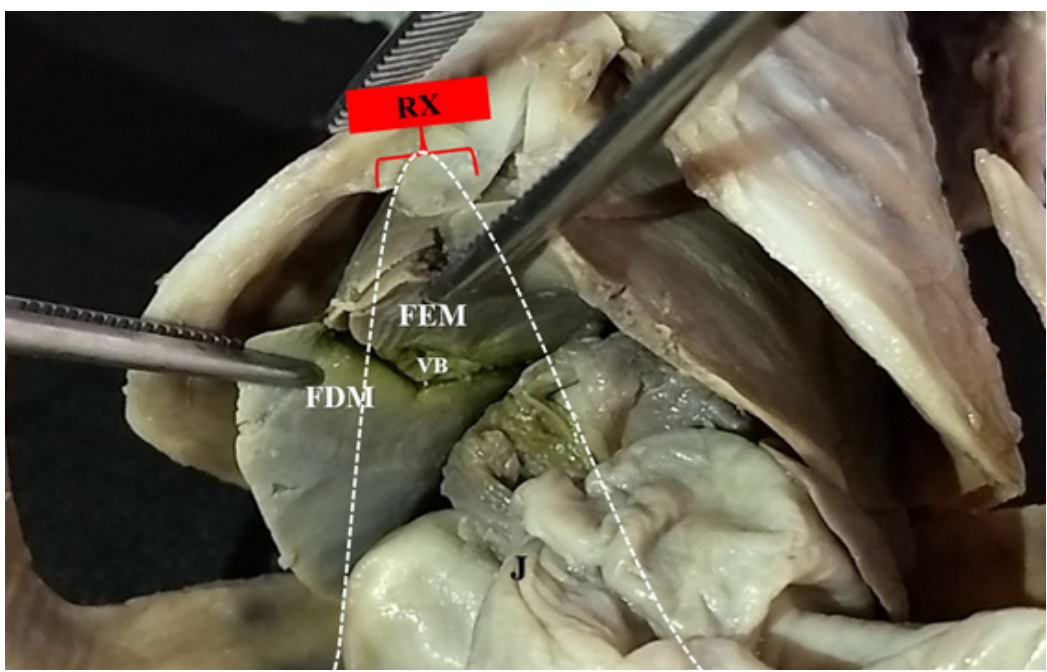

Figura 3: Fotomacrografia da cavidade abdominal de espécime jovem, macho, de $D$. albiventris revelando a região xifoidea (RX) com o lobo hepático esquerdo medial (FEM), lobo hepático direito medial (FDM), vesícula biliar (VB) e jejuno (J).

*As linhas tracejadas de cor branca delimitam aproximadamente a localização de regiões abdominais.
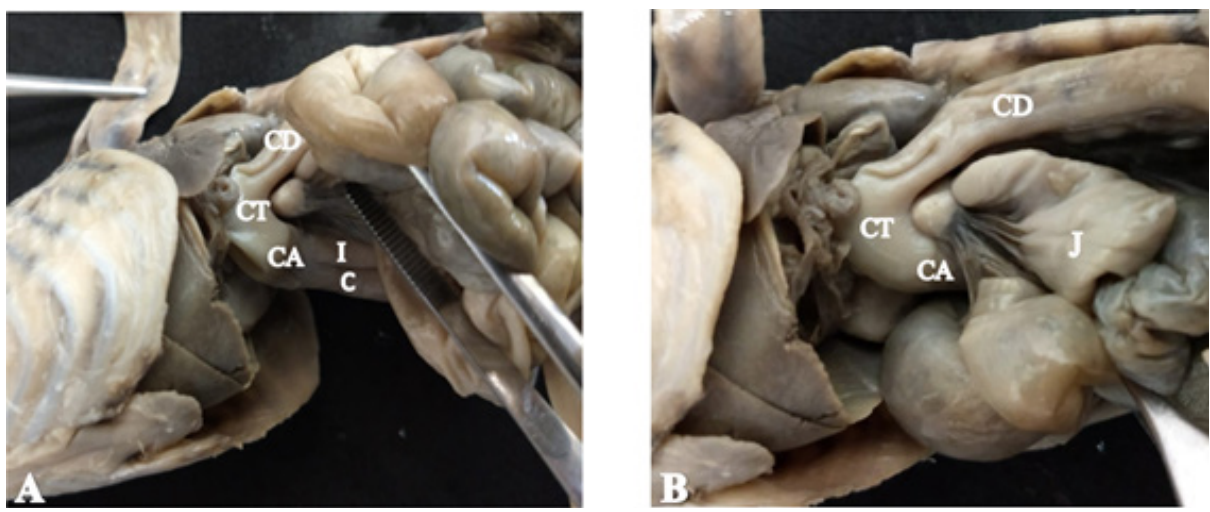

Figura 4: Fotomacrografia da cavidade abdominal de espécime jovem, macho, de $D$. albiventris demonstrando porções do intestino delgado e do intestino grosso (A e B): ceco (C), íleo (I), cólon ascendente (CA), cólon transverso (CT), cólon descendente (CD) e jejuno (J) 



Figura 5: Fotomacrografia da cavidade abdominal de espécime jovem, macho, de D. albiventris, revelando em A região xifoidea $(R X)$ com o fígado $(F)$ e jejuno $(J)$, região umbilical $(R U)$ com o jejuno $(J)$, região púbica (RP) com a vesícula urinária (VU) e em B região inguinal esquerda (RIE) com partes do cólon descendente (CD), reto (RT) e vesícula urinária (VU). As setas de cor branca estão demostrando o osso epipúbico direito. ${ }^{*}$ As linhas tracejadas de cor branca delimitam aproximadamente a localização de regiões abdominais

\begin{tabular}{|c|c|c|}
\hline Região Hipocondríaca direita & Região Xifoidea & $\begin{array}{l}\text { Região Hipocondríaca } \\
\text { esquerda }\end{array}$ \\
\hline $\begin{array}{l}\text { Fígado (processo caudado do } \\
\text { lobo caudado, lobo hepático } \\
\text { direito lateral e parte do lobo } \\
\text { hepático direito medial) } \\
\text { Rim direito } \\
\text { Glândula adrenal direita } \\
\text { Duodeno (parte cranial e parte } \\
\text { descendente) } \\
\text { Pâncreas }\end{array}$ & $\begin{array}{l}\text { Fígado (parte do lobo hepático } \\
\text { direito medial e parte do lobo } \\
\text { hepático esquerdo medial) } \\
\text { Vesícula biliar } \\
\text { Jejuno }\end{array}$ & $\begin{array}{l}\text { Rim esquerdo } \\
\text { Glândula adrenal esquerda } \\
\text { Baço } \\
\text { Fígado (lobo hepático esquerdo } \\
\text { lateral e parte do lobo hepático } \\
\text { esquerdo medial) } \\
\text { Estômago }\end{array}$ \\
\hline $\begin{array}{l}\text { Região abdominal lateral } \\
\text { direita }\end{array}$ & Região umbilical & $\begin{array}{l}\text { Região abdominal lateral } \\
\text { esquerda }\end{array}$ \\
\hline $\begin{array}{l}\text { Duodeno descendente } \\
\text { Ceco } \\
\text { Jejuno } \\
\text { Prega ileocecal } \\
\text { Prega cecocólica }\end{array}$ & Jejuno & $\begin{array}{l}\text { Cólon descendente } \\
\text { Jejuno }\end{array}$ \\
\hline Região inguinal direita & Região púbica & Região inguinal esquerda \\
\hline $\begin{array}{l}\text { Vesícula urinária } \\
\text { Parte cranial do osso epipúbico } \\
\text { direito }\end{array}$ & $\begin{array}{l}\text { Vesícula urinária } \\
\text { Ossos epipúbicos direito e } \\
\text { esquerdo }\end{array}$ & $\begin{array}{l}\text { Vesícula urinária } \\
\text { Cólon descendente } \\
\text { Reto } \\
\text { Parte cranial do osso epipúbico } \\
\text { esquerdo }\end{array}$ \\
\hline
\end{tabular}

Figura 6: Descrição dos principais órgãos e estruturas identificados nas subdivisões das regiões abdominais cranial, média e caudal em $D$. albiventris 


\section{Discussão}

Neste estudo, verificou-se que vários órgãos localizados na região abdominal dos cadáveres dissecados da espécie $D$. albiventris, apresentaram estruturas e posições similares aos dos caninos, porém, alguns órgãos e a localização de determinadas estruturas apresentaram particularidades importantes.

O baço dos cadáveres dissecados encontrou-se localizado na região hipocondríaca esquerda, em íntima relação com a curvatura maior do estômago, apresentando um formato irregular, corroborando com a descrição de Pinto et al. (2005), que estudou a anatomia esplênica da espécie referida. Um cadáver (com estômago repleto) apresentou o baço posicionado mais caudalmente quando comparado com os outros três (com estômagos parcialmente preenchidos), entretanto, a posição do baço depende do grau de distensão gástrica, em razão do curto ligamento gastrolienal (Budras et al. 2007).

Ambos os rins se encontraram localizados no teto da cavidade abdominal, lisos, de coloração acastanhada e em formato de feijão, corroborando com o estudo de Peçanha et al. 2020, realizado em animais da espécie $D$. aurita. No presente estudo, observou-se variação na posição dos rins em um cadáver; Peçanha et al. 2020, também descreveram variações na esqueletopia renal e ainda observaram maiores variações na esqueletopia do rim esquerdo, no atual estudo, apenas um cadáver apresentou ambos os rins localizados mais caudalmente, quando comparado com os outros três animais, não sendo observada a maior frequência de variação na posição do rim esquerdo, entretanto, há necessidade de mais pesquisas, devido ao pequeno número de cadáveres dissecados.

Na região xifoidea, pode-se observar o fígado e a vesícula biliar, a espécie descrita não possuiu o lobo hepático quadrado, particularidade também exposta por Neto (2000) em seu estudo que teve por objetivo descrever a segmentação hepática no $D$. albiventris, portanto, o fígado da espécie referida apresenta uma divisão de cinco lobos, diferenciando-se dos principais mamíferos domésticos, inclusive de indivíduos que pertencem à mesma família, como o Gracilinanus microtarsus que segundo Lobo et al. (2014), apresenta o lobo hepático quadrado totalizando seis lobos. Devido à ausência do lobo hepático quadrado, a vesícula biliar localiza-se entre os lobos hepáticos mediais direito e esquerdo.

$\mathrm{Na}$ região abdominal média, foram identificadas partes do intestino delgado (duodeno e jejuno) apresentando características e posições semelhantes às encontradas em carnívoros e porções do intestino grosso (ceco e cólon).

Com relação a descrição anatômica do intestino grosso da espécie $D$. albiventris a literatura encontra-se escassa. Os cadáveres dissecados exibiram um ceco desenvolvido e alongado, diferente do ceco dos caninos que é curto e espiralado (Budras et al. 2007), esses achados assemelham-se aos encontrados por Almeida (2017) que descreve o sistema digestório do $D$. marsupialis. Cáceres (2005), expõe que o ceco desenvolvido nas espécies $D$. aurita e $D$. albiventris serve para o acúmulo e fermentação de alimentos, e absorção de água, vitamina e eletrólitos.

O óstio ileal encontrou-se ao lado do óstio cecocólico, na Figura 4 é possível observar a comunicação do íleo e do ceco com o cólon ascendente, essa característica também é encontrada em caninos (Budras et al. 2007).

O cólon apresentou-se dividido em três segmentos. Em todos os cadáveres dissecados identificou-se uma porção extremamente curta que segue cranialmente no antímero direito (cólon ascendente), logo se desloca para o antímero esquerdo, formando um segmento transversal (possível cólon transverso) e progride caudalmente (cólon descendente), semelhante ao dos carnívoros (Konig e Liebich 2004). Porém, diferindo de indivíduos pertencentes ao mesmo gênero ou família, Almeida (2017) relata que o cólon da espécie $D$. marsupialis é saculiforme não citando subdivisões, já Lobo et al. (2014) identifica a presença de duas porções (cólon ascendente e descendente) em G. microtarsus (espécie pertencente à família Didelphidae). No presente estudo constatou-se a presença das porções apresentadas por Lobo et al. (2014), além de uma terceira parte compatível com o cólon transverso presente em mamíferos domésticos (Figura 4).

Na região abdominal caudal observou-se uma particularidade importante, a presença dos ossos epipúbicos, que são dois ossos longos e finos que articulam com o púbis, há pouco estudo referente a sua morfologia. Diferentes funções foram atribuídas à esses ossos, foi proposto que eles servem como um mecanismo de suporte para o marsúpio e a prole que se encontra em seu interior, auxiliando a musculatura no suporte do abdômen (White 1989); ainda, foi afirmado que os ossos epipúbicos atuam como uma alavanca para facilitar a rigidez do corpo através dos membros durante a caminhada e corrida ( Reilly e White 2003) e mais recentemente foi descrito por Cervantes e Oviedo-Martinez (2020), que estes ossos são um marco importante do dimorfismo sexual em $D$. virginiana.

O presente estudo através da descrição da anatomia topográfica abdominal de animais jovens da espécie $D$. albiventris, além de trazer informações inéditas importantes para o estudo morfológico da espécie, oferece subsídios para os profissionais relacionados a área de clínica, cirurgia e de diagnóstico por imagem de animais silvestres, indubitavelmente, mais pesquisas são necessárias, devido a baixa amostragem e a idade dos animais.

\section{Conclusão}

A estrutura e a localização de vários órgãos presentes nas diferentes regiões abdominais da espécie $D$. albiventris assemelham-se aos padrões anatômicos dos caninos, entretanto, há particularidades importantes; como a presença dos ossos epipúbicos, a ausência do lobo hepático quadrado e a presença de um ceco bem desenvolvido; algumas características diferindo inclusive de indivíduos do mesmo gênero ou família, como o cólon dividido em três segmentos, demostrando a importância do conhecimento anatômico detalhado para cada espécie. 


\section{Referências}

ALMEIDA, M.D.S. Aspectos morfológicos do tubo digestório do gambá Didelphis marsupialis (Linnaeus, 1758). 2017. 32 f. Monografia (Bacharel/Licenciado em Ciências Biológicas) Universidade Federal do Maranhão - Maranhão, 2017.

BORTOLINI, Z.; MATAYOSHI, P.M; SANTOS, R.V; DOICHE, D.P; MACHADO, V.M.V; TEIXEIRA, C.R; VULCANO, L.C. Arquivo Brasileiro de Medicina Veterinária e Zootecnia, v.65, n.4, p.12471252, 2013.

BUDRAS, K-D.; McCARTHY. P.H.; FRICKE, W.; RICHTER, R. Anatomy of the Dog. Hannover, Germany: Schlütersche, 2007. $218 p$.

CÁCERES, N.C. Comparative lengths of digestive tracts of seven didelphid marsupials (Mammalia) in relation to diet. Revista Brasileira de Zoologia, v. 22, p.181-185, 2005.

CERVANTES, F.A.; OVIEDO-MARTÍNEZ, V. Epipubic bones of the Virginia Opossum (Didelphis virginiana) from México. Therya, v.11, n.1, p.1-7, 2020.

ELFTMAN, H.O. Adaptações funcionais da pelve em marsupiais. Boletim do Museu Americano de História Natural, v.58, p.189-232, 1929.

INTERNATIONAL COMITTEE ON VETERINARY GROSS ANATOMICAL NOMENCLATURE. Nomina anatômica veterinária. $6^{a}$ edição. Ithaca: Word Association of Veterinary Anatomists, 2017. $160 \mathrm{p}$.

KÖNIG, H.E.; LIEBICH, H.G. Anatomia dos animais domésticos. Porto Alegre: Artmed, 2004. 788p.

LINDEMANN, T. Estudo da distribuição e dos territórios das artérias cerebrais rostral, média e caudal e cerebelares rostral, média e caudal na superfície do encéfalo em Didelphes albiventris (gambá). 2002. 154f. Tese (Doutorado em Ciências Veterinárias) - Programa da Pós-graduação em Ciências veterinárias - Universidade Federal do Rio Grande do Sul, Porto Alegre, 2002.
LOBO, L.M.; SANTOS, A.C. DOS.; ROSA, R.A.; AMBROSIO, C.E.; BRIANI, D.C.; COSTA, G.M.; CARVALHO, A.F.; MANÇANARES, C.A.F. Estudo macroscópico do aparelho digestório de Gracilinanus microtarsus (Wagner, 1842) (Mammalia: Didelphidae). Biotemas, v.27, n.1, p.109-120, 2014. Disponível em: <https://periodicos.ufsc.br/index.php/biotemas/ article/view/30206>. Acesso em: 19 jan. 2021.

NETO, R.A.F. Morfologia externa do fígado e principais ramificações da veia porta intra-hepática no gambá (Didelphis albiventris). Salusvita, Bauru, v. 19, n. 2, p. 53-61, 2000.

PEÇANHA, S.V et al. Anatomical characterisation of the kidneys of Didelphis aurita (Didelphimorphia: Didelphidae). Folia Morphol, v.79, n.4, p.805-810, 2020.

PINTO, J.R.C.; SILVA, M.R.F.B.M.; FILHO, J.G. Estudo da anatomia do baço do gambá (Didelphis albiventris). Veterinária Notícias, v. 11, n.2, p. 19-21, 2005.

PREUSS, J.F. Composição e caracterização da fauna de mamíferos de médio e grande porte atropelados em trecho da BR-282, Oeste do Estado de Santa Catarina. Unoesc. \& ciência ACBS, v.6, n. 2, p.179-186, 2015.

REILLY, S.M.; WHITE, T.D. Padrões motores hipaxiais e a função dos ossos epipúbicos em mamíferos primitivos. Science, v.299, p.400-402, 2003.

SANTOS, F.A.; NETO, G.B.P.; RABELO, R.C. Protocolo FAST ABCDE de Ultrassonografia em Urgências. In: RABELO, R.C. Emergências de Pequenos Animais:

Condutas Clínicas e Cirúrgicas no Paciente Grave. $1^{\text {a }}$ Edição. Rio de Janeiro: Elsevier, p. 692-705, 2012.

WHITE, T.D. Uma análise da função óssea epipúbica em mamíferos usando a teoria de escala. Journal of Theoretical Biology, v.139, p.189-232, 1989. 